Revista Arbitrada Interdisciplinaria KOINONIA

Año VI. Vol VI. N². Edición Especial: Educación III. 2021

Hecho el depósito de Ley: FA2016000010 ISSN: 2542-3088

FUNDACIÓN KOINONIA (F.K). Santa Ana de Coro. Venezuela.

Dra. Carlina Leonor García-Oberto

http://dx.doi.org/10.35381/r.k.v6i4.1567

\title{
Las innovaciones educativas post-pandemia
}

A lo largo del tiempo, la innovación ha sido un aspecto de suma relevancia, debido a que ha sido un gran aliado del hombre a través de su existencia aunado a la creatividad. Por ende, es menester hablar de esta como punto clave para el ajuste a las diversas transformaciones del día a día. En la actualidad, la innovación parte de los novedosos descubrimientos del hombre desde enfermedades como la pandemia de COVID- 19 hasta productos generados para la disolución de esta o estas. También emerge del uso de herramientas tecnológicas que facilitan la interacción desde diversos campos educativos, sociales, culturales, entre otros. En relación a ello, cabe citar a Camacho et al. (2020), quienes manifiestan lo siguiente:

La institucionalización de la tecnología e innovación, condujo cambios organizacionales a nivel mundial, incursionando en todos los ámbitos, desde empresariales, económico, político, educativo, entre otros; con la intención de crear sistemas que permitieran aumentar la productividad con resultados satisfactorios, manejar datos eficientemente y generar respuestas en el menor tiempo. (p. 464)

Actualmente, las TIC y sus usos constituyen los medios esenciales de la educación, ya que debido a la pandemia antes mencionada, los docentes en el ámbito educativo, han logrado dar continuidad a su proceso educativo mediante el uso de recursos novedosos como las TIC. A este respecto, Camacho et al. (2020) agregan lo siguiente:

A pesar de las desavenencias, las desigualdades entre países latinoamericanos, disparidades de acceso a los dispositivos digitales o uso de un sistema de conexión eficiente; el uso de la tecnología permitió cumplir los objetivos académicos establecidos, dependiendo del contexto de cada país o de cada población inmersa, que apoyada en el internet o señales televisivas, logró impedir la suspensión del año escolar en curso, demostrando lo prescindible de la tecnología, en especial la educativa en el sistema académico. (p. 468)

En este particular, vale plantarse las siguientes interrogantes: ¿cuáles recursos han sido mayormente empleados por los educadores? Y ¿cuáles han generado mejores aportes? 
La presente editorial tiene como enfoque central destacar la importancia de 'las innovaciones educativas post-pandemia'. En este sentido, Camacho et al. (2020), aseveran que a raíz de la pandemia:

... Organizaciones como UNESCO, establecieron proyectos con estrategias masivas a corto plazo, para aportar soluciones ante la contingencia apoyadas en la tecnología, ya sea a través del internet o medios más comunes como la televisión. Es decir, cada país, de acuerdo a sus posibilidades y situación está aplicando distintas estrategias para atender las necesidades educativas que se presentan ante la suspensión de clases presenciales. (p. 468)

En tal sentido, se puede precisar que las herramientas más comúnmente empleadas han sido el internet y la televisión; asimismo, han contribuido de forma significativa en la educación. No obstante, este es un tema que requiere de profundización y análisis; por ello, la presente editorial, la cual, tal como se expuso anteriormente, está orientada a la innovación post- pandemia, supone una visión reflexiva del quehacer educativo en función de los beneficios que aportan lo novedoso y lo creativo a los desafíos de la actualidad por causa de la pandemia.

Desde esta visión, la Revista Arbitrada Interdisciplinaria Koinonía, abre sus puertas a la diversidad de enfoques, experiencias y perspectivas que, de una u otra forma, contribuyan con la consolidación del aprendizaje de los individuos, enseñándolos a superar las dificultades, mediante el aprovechamiento de diversas herramientas propicias para el mejoramiento del entorno educativo y social.

\section{Dra. Carlina Leanor García Oberto}

academico@iieakoinonia.org

Instituto de Investigación y Estudios Avanzados Koinonía

Venezuela

https://orcid.org/0000-0002-3497-9187 